\title{
Estimation of Pore Size Distribution of Amorphous Silica-Based Membrane by the Activation Energies of Gas Permeation
}

\author{
Guozhao Ji ${ }^{1,2, *} \mathbb{0}$, Xuechao Gao ${ }^{3,4}$, Simon Smart ${ }^{1}$, Suresh K. Bhatia ${ }^{4} \oplus$, Geoff Wang ${ }^{4}$, \\ Kamel Hooman ${ }^{5}$ and João C. Diniz da Costa ${ }^{1}$ (D)
}

1 FIM ${ }^{2}$ Lab-Functional Interfacial Materials and Membranes Laboratory, School of Chemical Engineering, the University of Queensland, Brisbane, QLD 4072, Australia; s.smart@uq.edu.au (S.S.); j.dacosta@eng.uq.edu.au (J.C.D.d.C.)

2 School of Environmental Science and Technology, Dalian University of Technology, Dalian 116024, China

3 State Key Laboratory of Materials-Oriented Chemical Engineering, College of Chemical Engineering, Nanjing Tech University, 5 Xinmofan Road, Nanjing 210009, China; xuechao.gao@njtech.edu.cn

4 School of Chemical Engineering, the University of Queensland, Brisbane, QLD 4072, Australia; s.bhatia@uq.edu.au (S.K.B.); gxwang@uq.edu.au (G.W.)

5 School of Mechanical and Mining Engineering, the University of Queensland, Brisbane, QLD 4072, Australia; k.hooman@uq.edu.au

* Correspondence: guozhaoji@dlut.edu.cn or guozhao.ji@uqconnect.edu.au; Tel.: +86-0411-8470-6679; Fax: +86-0411-8470-6679

Received: 31 October 2018; Accepted: 21 November 2018; Published: 23 November 2018

\begin{abstract}
Cobalt oxide silica membranes were prepared and tested to separate small molecular gases, such as $\mathrm{He}\left(d_{\mathrm{k}}=2.6 \AA\right)$ and $\mathrm{H}_{2}\left(d_{\mathrm{k}}=2.89 \AA\right)$, from other gases with larger kinetic diameters, such as $\mathrm{CO}_{2}\left(d_{\mathrm{k}}=3.47 \AA\right)$ and $\operatorname{Ar}\left(d_{\mathrm{k}}=3.41 \AA\right)$. In view of the amorphous nature of silica membranes, pore sizes are generally distributed in the ultra-microporous range. However, it is difficult to determine the pore size of silica derived membranes by conventional characterization methods, such as $\mathrm{N}_{2}$ physisorption-desorption or high-resolution electron microscopy. Therefore, this work endeavors to determine the pore size of the membranes based on transport phenomena and computer modelling. This was carried out by using the oscillator model and correlating with experimental results, such as gas permeance (i.e., normalized pressure flux), apparent activation energy for gas permeation. Based on the oscillator model, $\mathrm{He}$ and $\mathrm{H}_{2}$ can diffuse through constrictions narrower than their gas kinetic diameters at high temperatures, and this was possibly due to the high kinetic energy promoted by the increase in external temperature. It was interesting to observe changes in transport phenomena for the cobalt oxide doped membranes exposed to $\mathrm{H}_{2}$ at high temperatures up to $500{ }^{\circ} \mathrm{C}$. This was attributed to the reduction of cobalt oxide, and this redox effect gave different apparent activation energy. The reduced membrane showed lower apparent activation energy and higher gas permeance than the oxidized membrane, due to the enlargement of pores. These results together with effective medium theory (EMT) suggest that the pore size distribution is changed and the peak of the distribution is slightly shifted to a larger value. Hence, this work showed for the first time that the oscillator model with EMT is a potential tool to determine the pore size of silica derived membranes from experimental gas permeation data.
\end{abstract}

Keywords: activation energy; pore size distribution; silica based membrane; effective medium theory; gas separation 


\section{Introduction}

Microporous silica $\left(\mathrm{SiO}_{2}\right)$ membrane has attracted significant research attention for gas separation, including $\mathrm{H}_{2}$ separation which is an energy carrier of great interest whilst also being a precursor for the production of chemical products [1-4]. The development of silica membranes was born out of a desire to control pore sizes at a molecular level. By tuning the pore size of silica membranes, the permeation of gas molecules is affected. As a result, gases with smaller kinetic diameters tend to permeate fast through the silica membranes whilst the permeation of the larger kinetic diameter gases are very slow or hindered. The initial development of silica membranes in the late 1980s and early 1990s was based on a sol-gel method using the conventional silica precursor tetraethyl orthosilicate (TEOS) [5-7]. A major development in silica membranes occurred with embedding metal oxides in the silica matrix. Since then, there have been a significant number of reports on metal oxide silica membranes, including those containing oxides of nickel [8,9], cobalt [10-14], niobium [15], palladium [16], zirconium [17], titanium [18] and aluminum [19]. A special feature of these membranes were high gas selectivities at high temperatures, which is of interest in several chemical engineering process applications. Subsequently, research groups reported on the use of binary mixed metal oxide in silica membranes, including those containing cobalt iron oxides [20,21], palladium cobalt oxide [22] and lanthanum cobalt oxide [23]. This allowed interesting pore size tailoring by reducing only a single metal oxide in the silica matrix, whilst the other one was left in the oxidized state. Nevertheless, based on the number of publications, cobalt oxide silica membranes remained the most popular metal oxide silica membranes, due to very high gas selectivity close to values of 1000 [24].

According to the molecular sieve mechanism, the most important parameter of a silica based membrane is the pore size. The determination of pore sizes in silica derived matrices is generally carried out by conventional characterization techniques, such as $\mathrm{N}_{2}$ adsorption. This technique uses xerogels (i.e., dry gel) which is generally gelled in bulk. As bulk evaporation and gelation is very slow compared to thin film (30 nm thickness) deposition on substrates, it is known that the structures of xerogel and thin film are not equivalent. For instance, the properties of a deposited thin film may be quite different, due to non-equivalent gelation and drying conditions [25]. Hence, $\mathrm{N}_{2}$ adsorption on bulk silica xerogel is generally used as a qualitative measure of thin film structures. Other more complex techniques have been applied to characterize xerogels and thin films. For instance, using Positron Annihilation Spectroscopy Duke and co-workers demonstrated that amorphous silica matrices have narrow tri-modal pore size distribution (PSD) at 2.5-4 $₫, 6.7-7.8 \AA$ and 12-14 $\AA$ [26]. Another technique to characterize the pore sizes of thin films deposited on substrate is molecular probing which uses gas molecules of different kinetic diameters to determine the average pore size, by plotting permeance versus the kinetic diameter of the gas tested.

A number of mass transfer studies suggested the gas permeation value was a result of membrane pore size and gas molecular size. In other words, if the pore size distribution (PSD) is known, the gas permeation data could be calculated from a proper model. The question in this work is whether it is possible to use a permeation model to derive the PSD, instead of the conventional approach of using permeation data of particular gases to determine the PSD. In a membrane gas permeation test, the measurable parameters are generally the gas permeance $\left(\mathrm{mol} \cdot \mathrm{m}^{-2} \cdot \mathrm{s}^{-1}\right)$ and the apparent activation $\left(\mathrm{kJ} \cdot \mathrm{mol}^{-1}\right)$ energy. Even though permeability $\left(\mathrm{mol} \cdot \mathrm{m}^{-1} \cdot \mathrm{s}^{-1}\right)$ is reported in some studies, it is not very reliable, due to the technical difficulty in accurately measuring the membrane thickness. Permeance may not be an ideal data for evaluating pore size, because it also depends on the membrane thickness. Fortunately, the apparent activation energy is not a function membrane thickness, and in principle it only depends on the pore size (pore diameter) and the size of gas molecule (molecular size).

If the gas permeation across a membrane follows an activated transport model, activation energy is a measure of the energy required by a gas molecule to permeate through a pore as follows: 


$$
E_{\mathrm{a}}=\frac{\mathrm{d} \ln (P / l)}{\mathrm{d}(R T)^{-1}}
$$

where $P$ is permeability and $l$ the membrane thickness. A number of studies reported apparent activation energies for different gases through the silica based membrane (Table 1). An interesting phenomenon is that $\mathrm{H}_{2}$ and He generally exhibit positive apparent activation energy, but other gases present negative apparent activation energy. This current study will employ the correlation between pore size and apparent activation energy to evaluate the pore size distribution of silica based membrane by the measured apparent activation energy, and use this pore size distribution to explain the observed transport phenomena.

Table 1. Apparent activation energies of gas permeation across silica based membranes.

\begin{tabular}{|c|c|c|c|c|c|}
\hline \multicolumn{5}{|c|}{ Apparent Activation Energy $\left(\mathrm{kJ} \cdot \mathrm{mol}^{-1}\right)$} & \multirow{2}{*}{ Reference } \\
\hline $\mathbf{H}_{2}$ & $\mathrm{He}$ & $\mathrm{CO}_{2}$ & $\mathbf{N}_{2}$ & Ar & \\
\hline $16.4 \sim 17.1$ & $16.2 \sim 17.1$ & - & - & - & [27] \\
\hline 2.2 & 2.8 & -9.8 & -5.4 & - & [28] \\
\hline $15.4 \sim 19.4$ & - & - & $8.5 \sim 11.9$ & - & [29] \\
\hline 12.8 & 20.7 & -20 & - & - & [24] \\
\hline- & 9.5 & - & -5.0 & - & [11] \\
\hline- & 13.6 & - & - & - & [30] \\
\hline 6 & - & - & - & - & [31] \\
\hline 4.91 & 4.70 & -2.91 & -1.41 & - & [14] \\
\hline 10.1 & - & -3.1 & - & -1.9 & [32] \\
\hline 14.1 & 7.7 & - & 12.3 & - & [33] \\
\hline$\sim 9$ & 7.2 & - & - & - & [34] \\
\hline
\end{tabular}

\section{Theory of Mass Transfer Through Membrane}

A general model of mass transfer is always expressed as a coefficient multiplied by a driving force as

$$
J=k \times f
$$

where $J$ is the mass transfer flux, $k$ is the mass transfer coefficient and $f$ is the driving force. The driving force of the gas permeation is usually the chemical potential, which can be reduced to gradient of pressure, concentration, depending on the system. The mass transfer coefficient can be permeability, diffusivity or other term depending on the term used for driving force. For membrane processing of gases, the pressure difference and permeate flux are the quantities generally determined from experimental measurements, so the most common form in membrane mass transfer is

$$
J=\left(\frac{P}{l}\right) \Delta p
$$

where membrane thickness $l$ is lumped together with permeability $P$ into a term called permeance $(P / l)$ which is a convenient form avoiding the difficulty in accurately measuring the thickness of silica thin films. Sometimes, silica thin films interpenetrate into the pores of porous of substrates, depending on the property of the sol and substrate. Hence, the membrane thickness is not always easy to determine.

\subsection{Activated Transport}

For ultra-microporous $\left(d_{\mathrm{p}}<5 \AA\right)$ material, the pore size of the silica thin-films is close to the Lennard Jones (L-J) diameter which results in overlap of the L-J potentials from the pore wall. In such cases, the L-J potential inside a pore could be several magnitudes higher than that of a flat surface. Therefore, the motion of gas molecules in a pore is not as free as in the bulky gas phase, instead it must be significantly affected by the potential fields. Pores of size close to the diameter of a gas 
molecule generally present a positive potential for the gas molecule. The potential becomes even higher with narrower pore size. To overcome the potential barrier inside a pore, the gas molecule needs activation energy to complete a successful penetration. Therefore, this type of mass transfer is called activated transport. Gas transport through silica based membranes generally follows activated transport $[10,35,36]$. The original expression of mass transfer across the membrane is given as [37-39]

$$
J=-q D \frac{1}{R T} \frac{\mathrm{d} \mu}{\mathrm{d} z}
$$

where $J$ is the permeate flux, $q$ the molar concentration of gas in the pore, $D$ the diffusivity, $R$ the gas constant, $T$ the temperature, $\mu$ the chemical potential and $z$ the space coordinate in the permeation direction.

Assuming equilibrium between the membrane adsorbate and the bulk gas phase, the following relationship for the chemical potential $[40,41]$ is applicable

$$
\mu=\mu_{0}+R T \ln p
$$

where $p$ is the absolute pressure.

Substituting Equation (5) in Equation (4) gives

$$
J=-D \frac{\mathrm{d} \ln p}{\mathrm{~d} \ln q} \frac{\mathrm{d} q}{\mathrm{~d} z}=-q D \frac{\mathrm{d} \ln p}{\mathrm{~d} q} \frac{\mathrm{d} q}{\mathrm{~d} z}=-D \Gamma \frac{\mathrm{d} q}{\mathrm{~d} z}=-D \frac{1}{1-\theta_{\text {ocp }}} \frac{\mathrm{d} q}{\mathrm{~d} z}
$$

where $\Gamma=q(\mathrm{~d} \ln p / \mathrm{d} q)$ is a thermodynamic factor, obtained as $\Gamma=1 /\left(1-\theta_{\text {ocp }}\right)$ for a Langmuir isotherm. $\theta_{\text {ocp }}$ is the fractional occupancy of the adsorbate (the ratio of adsorbate concentration to the maximum adsorbate concentration). As the silica membrane is designed for separating hot gas $\left(200-500{ }^{\circ} \mathrm{C}\right)$, the high temperature adsorption is very weak $\left(\theta_{\text {ocp }} \approx 0\right)$, so that the thermodynamic factor is $\Gamma=1 /\left(1-\theta_{\text {ocp }}\right) \approx 1$, and the permeate flux is finally approximated as

$$
J=-D \frac{\mathrm{d} q}{\mathrm{~d} z}
$$

The diffusivity $D$ is a function of temperature, and is activated. The temperature dependence generally obeys the Arrhenius relation

$$
D=D_{0} \exp \left(-\frac{E_{\mathrm{d}}}{R T}\right)
$$

where $D_{0}$ is a pre-exponential coefficient, and $E_{\mathrm{d}}$ is an activation energy. At high temperatures, the adsorption is weak and the Langmuir isotherm approaches Henry's law [42]

$$
q=K p
$$

$K$ is the Henry's constant and a function of temperature, following the van't Hoff relation:

$$
K=K_{0} \exp \left(\frac{Q}{R T}\right)
$$

where $K_{0}$ is a pre-exponential coefficient, and $Q$ is the heat of adsorption.

Equations (7)-(10) can be combined as

$$
J=-D_{0} K_{0} \exp \left(-\frac{E_{\mathrm{d}}-Q}{R T}\right) \frac{\mathrm{d} p}{\mathrm{~d} z}=-D_{0} K_{0} \exp \left(-\frac{E_{\mathrm{a}}}{R T}\right) \frac{\mathrm{d} p}{\mathrm{~d} z}
$$


$E_{\mathrm{a}}$ is the apparent activation energy for activated transport, which has a relation to $E_{\mathrm{d}}$ and $Q$ in Equation (12)

$$
E_{\mathrm{a}}=E_{\mathrm{d}}-Q
$$

Assuming a uniform pressure gradient, Equation (11) is simplified to

$$
J=D_{0} K_{0} \exp \left(-\frac{E_{\mathrm{a}}}{R T}\right) \frac{\Delta p}{l}
$$

The permeance $(P / l)$ is the coefficient between flux and pressure drop according to Equation (3), and is obtained as

$$
\left(\frac{P}{l}\right)=\frac{D_{0} K_{0}}{l} \exp \left(-\frac{E_{\mathrm{a}}}{R T}\right)
$$

the apparent activation energy is experimentally derived from the permeance measured at different temperatures. If Equation (14) is logarithmically transformed

$$
\ln \left(\frac{P}{l}\right)=\ln \left(\frac{D_{0} K_{0}}{l}\right)-\frac{E_{\mathrm{a}}}{R T}
$$

The slope of $\ln (P / l)$ to $-1 /(\mathrm{R} T)$ gives the apparent activation energy as indicated by Equation (1).

\subsection{Potential in Cylindrical Pores}

The motion of gas molecules in micro-pores is strongly affected by the potential inside the pore. The potential between two atoms based on the Lennard-Jones (L-J) potential is [43]

$$
\phi(\rho)=4 \varepsilon\left[\left(\frac{\sigma}{\rho}\right)^{12}-\left(\frac{\sigma}{\rho}\right)^{6}\right]
$$

where $\phi$ is the potential between two atoms, $\sigma$ the L-J collision diameter, $\varepsilon$ the L-J well depth, and $\rho$ the distance between the centers of two atoms. For two different atoms, the L-J collision diameter and L-J well depth are estimated by the Lorentz-Berthelot mixing rules [44,45]

$$
\begin{gathered}
\sigma_{\mathrm{AB}}=\frac{1}{2}\left(\sigma_{\mathrm{A}}+\sigma_{\mathrm{B}}\right) \\
\varepsilon_{\mathrm{AB}}=\sqrt{\varepsilon_{\mathrm{A}} \varepsilon_{\mathrm{B}}}
\end{gathered}
$$

In this work the pore is simplified as a cylinder consisting of L-J particles. It is important to clarify the definition of pore size beforehand (Figure 1). The diameter $(d)$ of the pore is defined as the distance from an oxygen particle center to the opposite oxygen particle center. The inner diameter $d_{\mathrm{i}}$ (surface to surface) is more relevant in size sieving, but is not unambiguously defined for soft-sphere L-J particles. Therefore, $d$ is used instead of $d_{\mathrm{i}}$ throughout this work and pore radius is $r_{\mathrm{p}}=d / 2$.

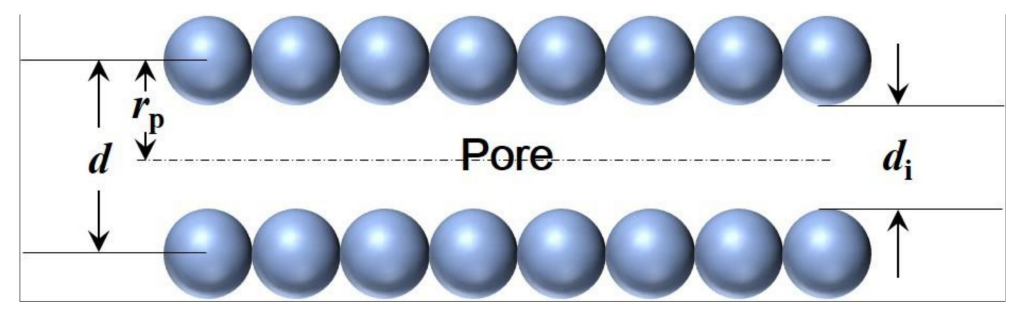

Figure 1. The pore of the silica membrane.

Equation (16) has provided the potential between two atoms. The potential in a pore is actually the summation from all the atoms which formed the pore. Calculating the potential inside a pore 
could be conducted by integrating all the atom-atom potentials geometrically. By assuming the pore is cylindrical, with radius $r$ (Figure 2), the potential distribution inside a pore is given by

$$
\begin{aligned}
\phi\left(r, r_{\mathrm{p}}\right) & =8 \varepsilon \eta_{\mathrm{d}} r_{\mathrm{p}} \int_{0}^{\frac{L}{2}} \int_{0}^{2 \pi}\left[\left(\frac{\sigma}{\rho}\right)^{12}-\left(\frac{\sigma}{\rho}\right)^{6}\right] \mathrm{d} \theta \mathrm{d} z \\
& =8 \varepsilon \eta_{\mathrm{d}} r_{\mathrm{p}} \int_{0}^{\frac{L}{2}} \int_{0}^{2 \pi}\left[\frac{\sigma^{12}}{\left(r_{\mathrm{p}}^{2}+r^{2}-2 r_{\mathrm{p}} r \cos \theta+z^{2}\right)^{6}}-\frac{\sigma^{6}}{\left(r_{\mathrm{p}}^{2}+r^{2}-2 r_{\mathrm{p}} r \cos \theta+z^{2}\right)^{3}}\right] \mathrm{d} \theta \mathrm{d} z
\end{aligned}
$$

where $r_{\mathrm{p}}$ is the pore radius, $L$ the pore length, $\eta_{\mathrm{d}}$ the surface atomic density on the pore wall and $r$ the radial coordinate with a range of $r \in\left[0, r_{\mathrm{p}}\right)$. The meaning of all the variables in Equation (19) are visually explained in Figure 2.

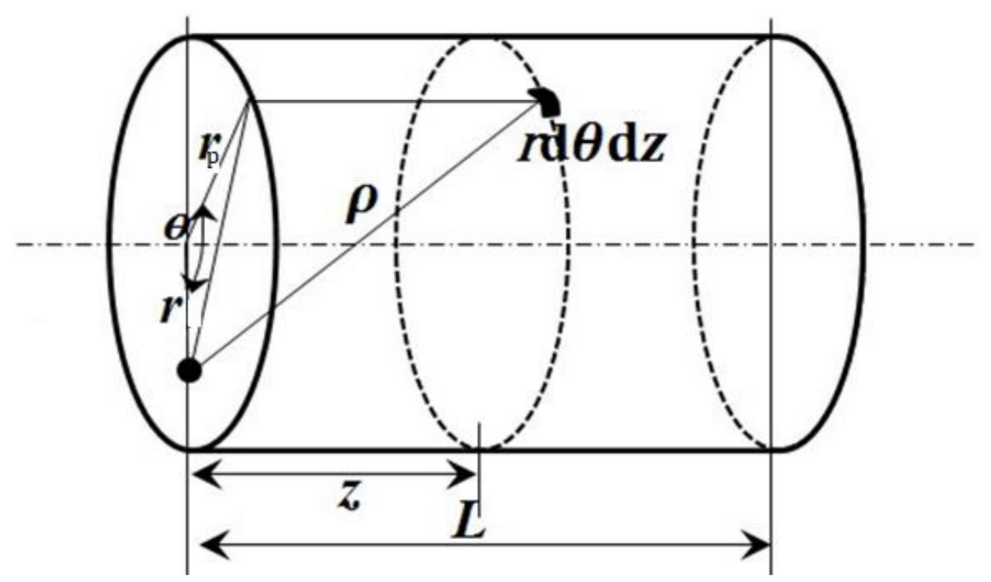

Figure 2. Geometrical simplification of a hydrogen molecule in a cylindrical pore.

An example of the $\mathrm{H}_{2}$ potential distribution based on Equation (19) inside a silica pore with varied pore sizes is displayed in Figure 3. It is the nature of gases to follow thermodynamic laws and seek the lowest potential as displayed in Figure 4.

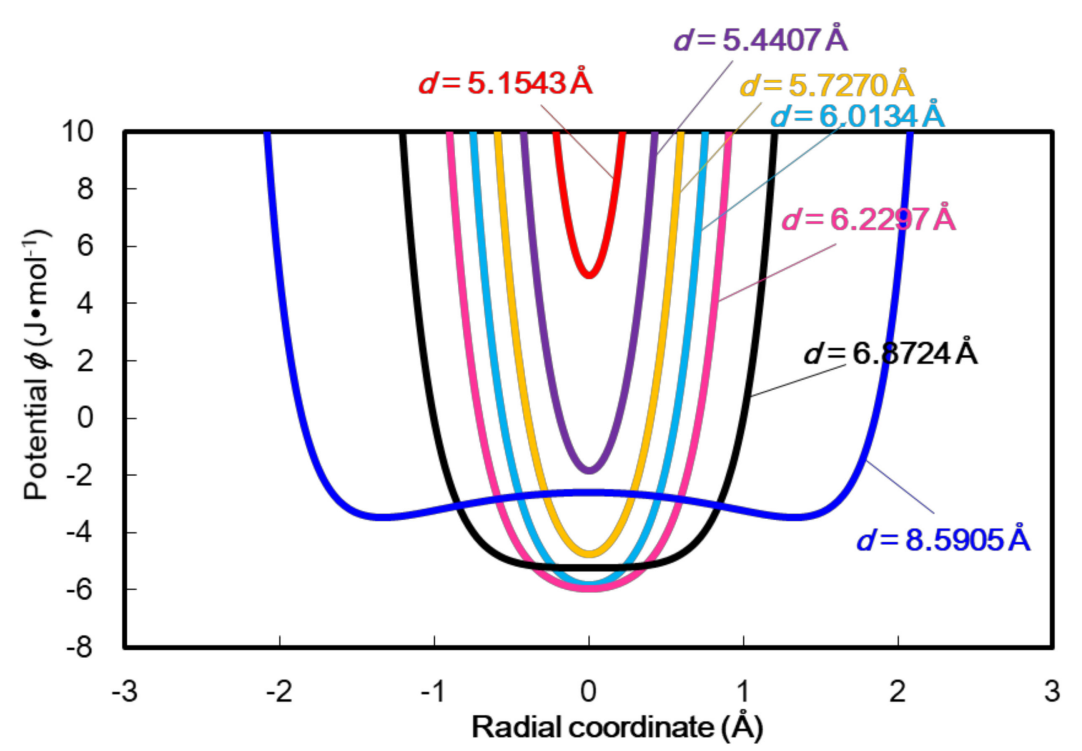

Figure 3. Hydrogen potential distribution inside cylindrical silica pores with different pore sizes. 


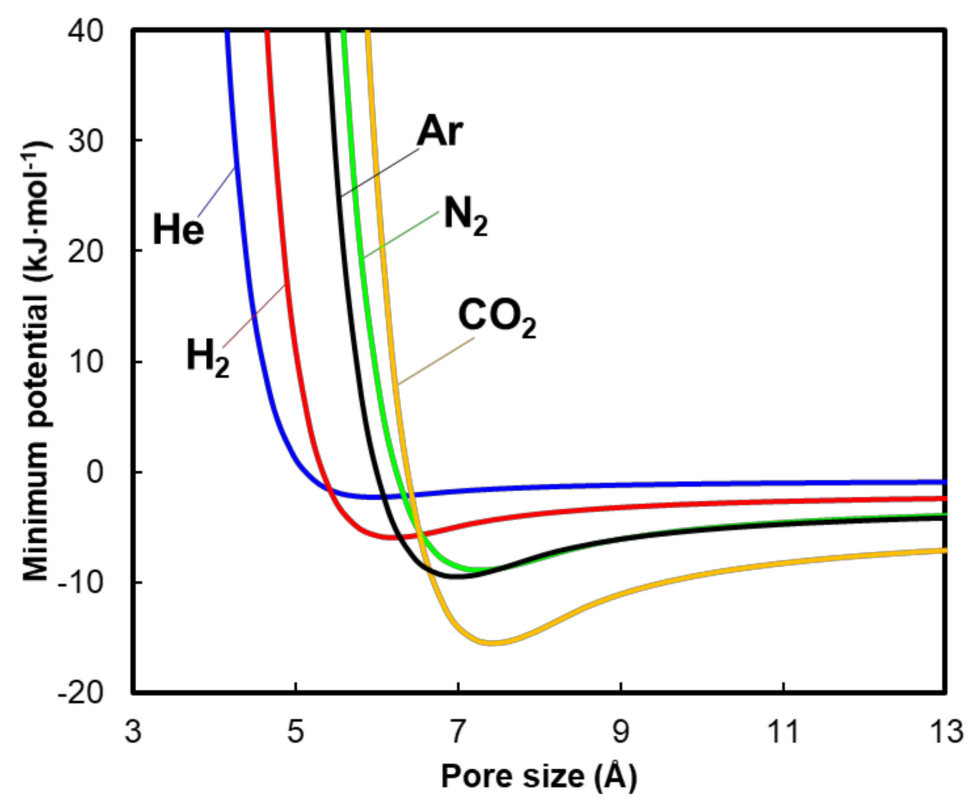

Figure 4. The minimum potential with respect to pore size, for different gases.

\subsection{Pore Size Distribution (PSD) Estimation of A Membrane}

Since a silica membrane is generally amorphous, there is a distribution of pore sizes and the pore size distribution of membrane differs from that in the sample powder for $\mathrm{N}_{2}$ adsorption test. The first reason is attributed to the effect from the substrate, which may consequently affect the pore structure of the membrane. The second reason is that the membrane has several layers and each layer has a different thermal history which results in variation in pore structure [46].

The pore size distribution of sample powder is usually characterized by gas adsorption which is operated at a low temperature. Pores smaller than adsorbate kinetic diameter are hardly detected by adsorption, as the L-J potential in a small pore is too repulsive for adsorbate molecules to enter. However, gas permeation is operated at high temperatures, for which gas molecules travel with high kinetic energy and have the possibility to access pores smaller than their diameter. Since such pores also contribute to the total permeation, the pore size distribution can be extracted from permeation data.

To this end, we consider a Rayleigh distribution of pore sizes for the silica matrix [47-53]

$$
f\left(r_{\mathrm{p}}\right)=\frac{\left(r_{\mathrm{p}}-r_{\mathrm{o}}\right)}{\left(r_{\mathrm{m}}-r_{\mathrm{o}}\right)^{2}} \exp \left[-\frac{\left(r_{\mathrm{p}}-r_{\mathrm{o}}\right)^{2}}{2\left(r_{\mathrm{m}}-r_{\mathrm{o}}\right)^{2}}\right]
$$

where $f\left(r_{\mathrm{p}}\right)$ is the distribution function, $r_{\mathrm{p}}$ is the possible pore radius, $r_{\mathrm{o}}$ is the minimum pore radius and $r_{\mathrm{m}}$ is the modal pore radius. When there is a pair of $\left(r_{0}, r_{\mathrm{m}}\right), f\left(r_{\mathrm{p}}\right)$ is the probability density of finding pores of which the size is $r_{\mathrm{p}}$. The oscillator model computes the permeate flow $\left(\mathrm{mol} \cdot \mathrm{s}^{-1}\right)$ of a pore with size $r_{\mathrm{p}}$, such that

$$
i=-\pi r_{\mathrm{p}}^{2} K\left(r_{\mathrm{p}}\right) D\left(r_{\mathrm{p}}\right) \nabla p
$$

and the conductance for permeation through a pore with size $r_{\mathrm{p}}$ is defined as

$$
\lambda\left(r_{\mathrm{p}}\right)=\pi r_{\mathrm{p}}^{2} K\left(r_{\mathrm{p}}\right) D\left(r_{\mathrm{p}}\right)
$$

The details of computing $D\left(r_{\mathrm{p}}\right)$ and $K\left(r_{\mathrm{p}}\right)$ are provided by Bhatia et al. [2,53,54]. The contribution of any pore size to the total bulk permeate flow depends on the pore size distribution. The total 
permeate bulk flow is the summation of the flow from all the pores. To calculate the total permeate flow, the effective medium theory (EMT) is generally applied [55-58]

$$
\int_{r_{\min }}^{r_{\max }} f\left(r_{\mathrm{p}}\right) \frac{\lambda\left(r_{\mathrm{p}}\right)-\lambda_{\mathrm{e}}}{\lambda\left(r_{\mathrm{p}}\right)+\left(\frac{N}{2}-1\right) \lambda_{\mathrm{e}}} \mathrm{d} r_{\mathrm{p}}=0
$$

where $f\left(r_{\mathrm{p}}\right)$ is the pore size number distribution, $N$ is the connectivity of pores, $r_{\min }$ and $r_{\max }$ are the minimum and maximum pore size. The solution $\lambda_{\mathrm{e}}$ of Equation (23) is the effective conductance of the entire membrane, which can be used to calculate the bulk permeate flux

$$
J=-\frac{\varepsilon \lambda_{\mathrm{e}}}{\tau_{\mathrm{T}} \pi\left\langle r_{\mathrm{p}}{ }^{2}\right\rangle} \nabla p
$$

where $\varepsilon$ is the porosity, $\tau_{\mathrm{T}}$ is the tortuosity and $\pi<r_{\mathrm{p}}{ }^{2}>$ is the mean pore cross section area. For a disordered network, the tortuosity is normally given by $[59,60]$

$$
\tau_{\mathrm{T}}=\frac{3(N+1)}{N-1}
$$

Equation (24) provides the bulk permeate flux. For a specific Rayleigh pore size distribution $f\left(r_{\mathrm{o}}, r_{\mathrm{m}}, r_{\mathrm{p}}\right)$, the bulk permeate flux at different temperatures can be obtained from the model above. When permeate fluxes at different temperatures are available, the bulk apparent activation energy is then calculated by Equations (1) and (15). This bulk apparent activation energy shows one-to-one correspondence to the pore size distribution $f\left(r_{\mathrm{o}}, r_{\mathrm{m}}, r_{\mathrm{p}}\right)$. By varying $r_{\mathrm{o}}$ and $r_{\mathrm{m}}$ of Equation (20), the calculated bulk apparent activation energy will change. The deviation of calculated apparent activation energy to the experimental apparent activation energy is defined as

$$
\frac{\left|E_{\mathrm{a}, \text { osc }}-E_{\mathrm{a}, \exp }\right|}{E_{\mathrm{a}, \exp }}=\frac{\left|E_{\mathrm{a}, \text { osc }}^{\mathrm{He}}-E_{\mathrm{a}, \exp }^{\mathrm{He}}\right|}{E_{\mathrm{a}, \exp }^{\mathrm{He}}}+\frac{\left|E_{\mathrm{a}, \text { osc }}^{\mathrm{H}_{2}}-E_{\mathrm{a}, \exp }^{\mathrm{H}_{2}}\right|}{E_{\mathrm{a}, \exp }^{\mathrm{H}_{2}}}
$$

It is assumed that the value $\left(r_{0}, r_{\mathrm{m}}\right)$ which gives the activation energy closest to the experimental activation energy provides the best representation of the membrane pore size distribution.

\section{Experiment}

\subsection{Sol-Gel Preparation and Membrane Coating}

The cobalt oxide silica sol-gel method involved mixing several chemical precursors is reported elsewhere [11]. Briefly, cobalt nitrate hexahydrate $\left(\mathrm{Co}\left(\mathrm{NO}_{3}\right)_{2} \cdot 6 \mathrm{H}_{2} \mathrm{O}, 98 \%\right.$, Sigma-Aldrich) was dissolved in $30 \mathrm{vol} . \%$ aqueous hydrogen peroxide $\left(\mathrm{H}_{2} \mathrm{O}_{2}, 30 \mathrm{wt} \%\right)$ and ethanol ( $\mathrm{EtOH}, 99 \%$, AR grade). Then tetraethoxysilane (TEOS, 99\%, Fluka) was added drop wise to form a final molar ratio of 255 ethanol:4 TEOS: $1 \mathrm{Co}\left(\mathrm{NO}_{3}\right)_{2} \cdot 6 \mathrm{H}_{2} \mathrm{O}: 9 \mathrm{H}_{2} \mathrm{O}_{2}: 40 \mathrm{H}_{2} \mathrm{O}$. The sol-gel was dip-coated on an alumina support purchased from the Energy Centre of the Netherlands (ECN). Each cobalt oxide silica layer was calcined up to $630^{\circ} \mathrm{C}$ in air at a ramping rate of $1{ }^{\circ} \mathrm{C} \cdot \mathrm{min}^{-1}$ and with a dwell time of $4 \mathrm{~h}$. A total of five layers were sequentially dip-coated on the outside surface of the alumina support and calcined to ensure defect-free membranes. The alumina support was composed of asymmetric layers. The top layer was derived from $\gamma$-alumina with an intrinsic pore size distribution around $4 \mathrm{~nm}$, and was coated on a mechanically robust porous $\alpha$-alumina substrate with the following dimensions: Length $\sim 70 \mathrm{~mm}$, external and internal diameters of 14 and $10 \mathrm{~mm}$, respectively. 


\subsection{Gas Separation Measurement}

The membrane module testing configuration is shown in Figure 5. A membrane tube was initially sealed by a set of Swagelok fittings, nut and graphite ferrule. After sealing, the membrane effective length was $48 \mathrm{~mm}$. The membrane was finally assembled into a cylindrical module, tested and adjusted until a leak free membrane/seal interface was achieved. Once the membrane was leak free, it was tested for $\mathrm{He}$ and $\mathrm{H}_{2}$ permeation from $100 \%$ of the pure feed gas. Then the mixed gases $\mathrm{He} / \mathrm{CO}_{2}$ and $\mathrm{H}_{2} / \mathrm{Ar}$ were tested down to $30 \% \mathrm{He}$ and $20 \% \mathrm{H}_{2}$ mixtures, respectively. The gas mixture testing included strong adsorbing gas (such as $\mathrm{CO}_{2}$ ) and non-adsorbing gas $(\mathrm{He})$ for the permeation for $\mathrm{He} / \mathrm{CO}_{2}$. The flow rate was measured by a bubble flow meter and the composition of the mixed gas was determined by Shimadzu gas chromatograph (GC).

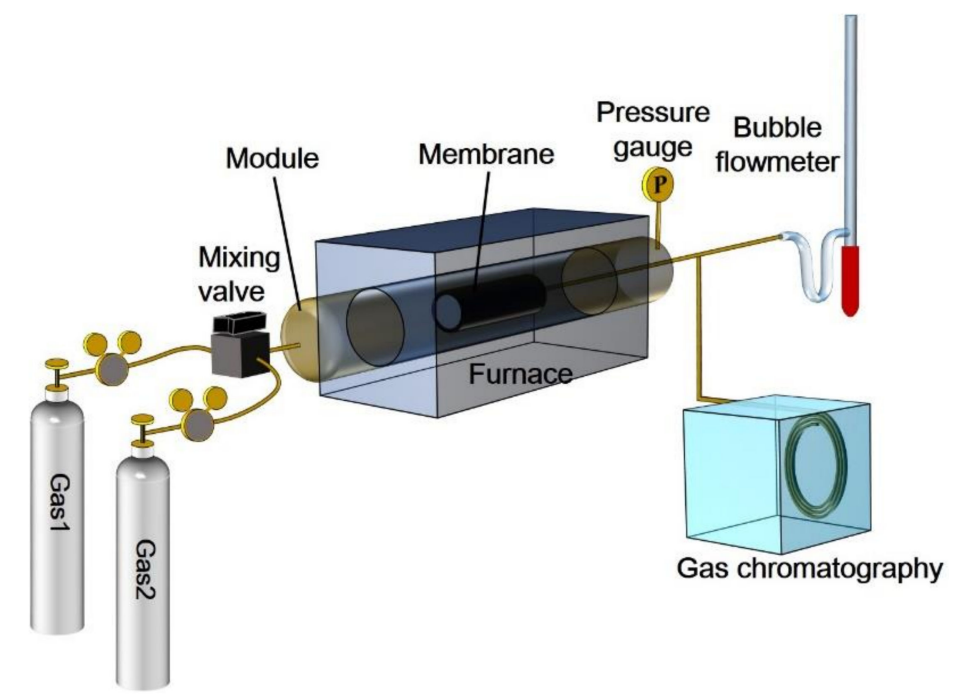

Figure 5. Diagram of the permeation/separation experimental set up.

\section{Results and Discussion}

In view of the asymmetric nature of the cobalt oxide silica membranes, gas permeation was also carried out on the substrate prior to dip coating with cobalt oxide silica sol-gel. This test was conducted to investigate the resistance level of the support alone. Figure 6 shows that the permeance of He and $\mathrm{H}_{2}$ across the uncoated support was $\sim 1 \times 10^{-5} \mathrm{~mol} \cdot \mathrm{m}^{-2} \cdot \mathrm{s}^{-1} \cdot \mathrm{Pa}^{-1}$, whilst for coated cobalt oxide silica support as a full membrane was $\sim 2 \times 10^{-8} \mathrm{~mol} \cdot \mathrm{m}^{-2} \cdot \mathrm{s}^{-1} \cdot \mathrm{Pa}^{-1}$. If the resistance is defined as the reciprocal of permeance, the resistance in the substrate only accounts for $\sim 0.2 \%$ of the total resistance which is much lower than the permeation experimental error of $\pm \sim 8 \%$. Therefore, the resistance of the substrate is ignored in the modelling in this work, and the transport of gases is assumed to be limited by cobalt oxide silica layers only.

Figure 7 shows the permeation test for 200 to $500{ }^{\circ} \mathrm{C}$ for $\mathrm{He} / \mathrm{CO}_{2}$ binary mixtures from $90 \% \mathrm{He}$ $\left(10 \% \mathrm{CO}_{2}\right)$ down to $10 \% \mathrm{He}\left(90 \% \mathrm{CO}_{2}\right)$. The feed pressure was kept constant at $6 \mathrm{~atm}$, and controlled by a back pressure valve. The permeate side was open to the atmosphere, to maintain pressure at $1 \mathrm{~atm}$. More details about the mixed gas permeation could be found in Ji et al. [61]. The $\mathrm{CO}_{2}$ single gas permeation proved to be too slow to be measured, and was considered below the measurable region of the bubble flow meter. It is interesting to observe in Figure 7 that the strong adsorbing gas of $\mathrm{CO}_{2}$ did not greatly affect the permeation of $\mathrm{He}$, which is a non-adsorbing gas under the tested conditions. The competitive adsorption effect is generally more prevalent in low temperature gas separation conditions, where the stronger adsorbing gas covers more surface and pores of the membrane, hindering the transport of the other gas in the membrane pores [62,63]. However, gas permeation was carried out at high temperatures, and the competitive adsorption effect barely affects the $\mathrm{He}$ 
permeation. It was observed that He permeate flow rate increased linearly as a function of the He feed fraction (or partial pressure), yielding a constant He permeance.

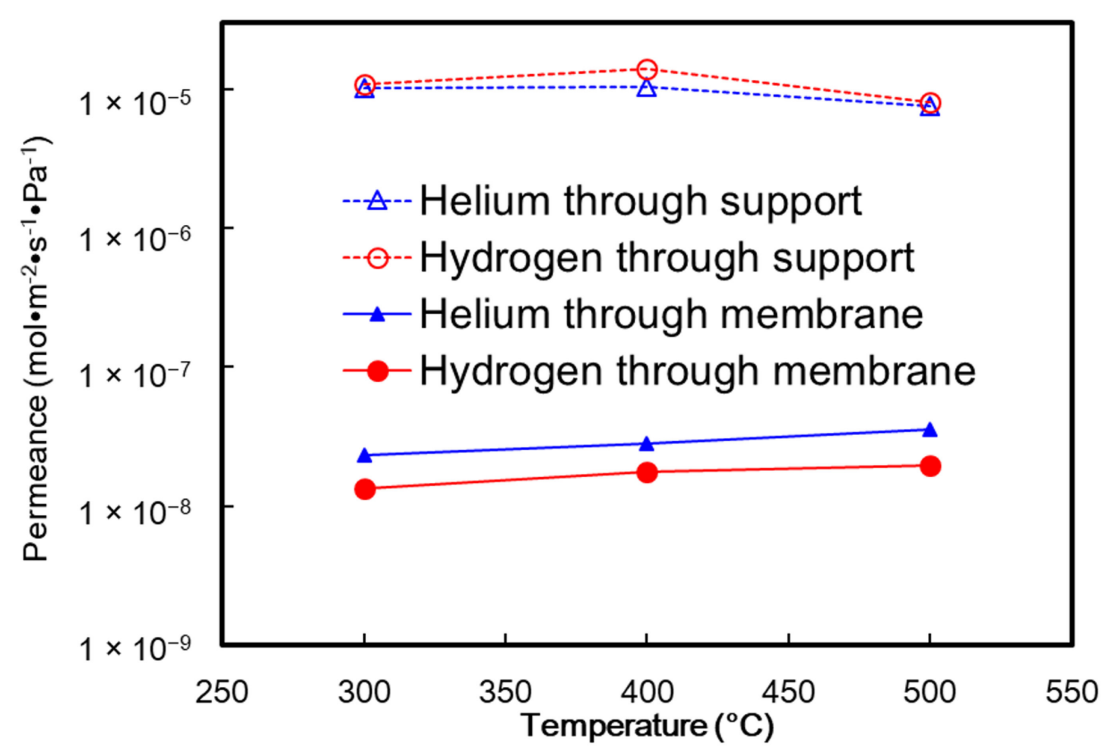

Figure 6. He and $\mathrm{H}_{2}$ permeances through cobalt oxide silica coated substrate and uncoated substrate as a function of temperature.

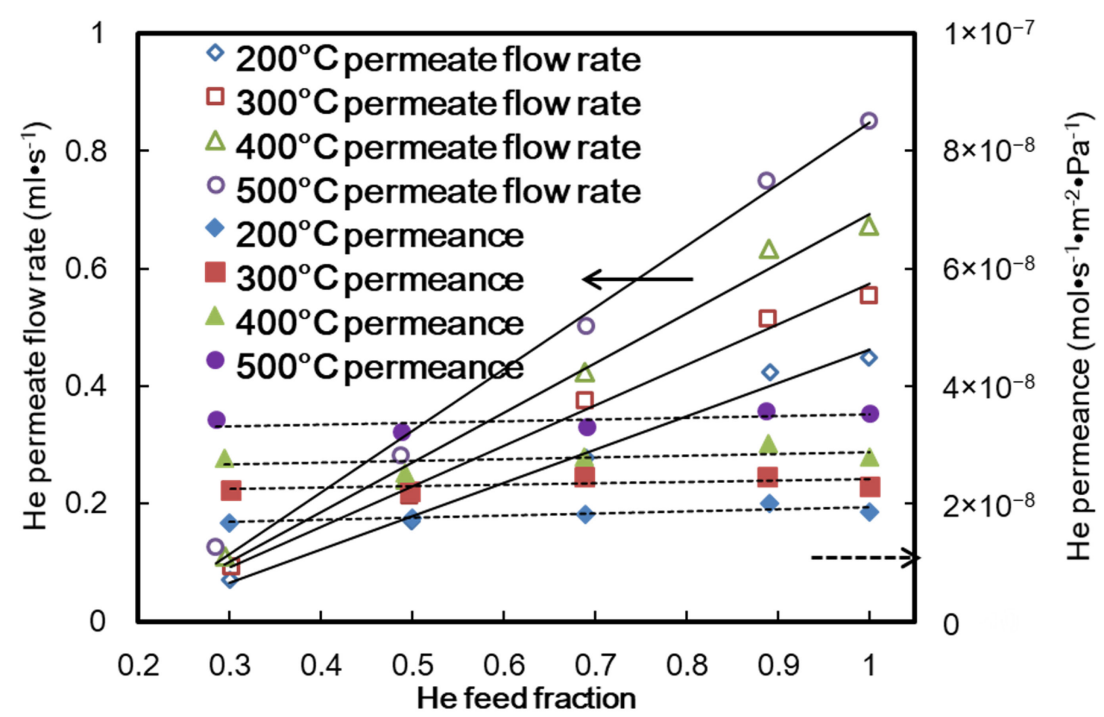

Figure 7. He permeation performance of cobalt oxide silica membrane.

Further work was carried out for $\mathrm{H}_{2}$ and Ar mixtures. Due to the catalytic effect of the cobalt oxide, mixtures of $\mathrm{H}_{2}$ and $\mathrm{CO}_{2}$ were not considered to avoid the reverse reaction of the water gas shift reaction, which would result in the production of $\mathrm{CO}$ and water vapor [64]. This would generate a quaternary mixture of $\mathrm{H}_{2}, \mathrm{CO}_{2}, \mathrm{CO}$ and $\mathrm{H}_{2} \mathrm{O}$. Hence, Ar was used as a subrogated molecule to maintain a binary gas mixture of $\mathrm{H}_{2} / \mathrm{Ar}$ instead of a multiple transient gas mixture. In addition, $\operatorname{Ar}\left(d_{k}=3.41 \AA\right)$ and $\mathrm{CO}_{2}\left(d_{k}=3.47 \AA\right)[65,66]$ have similar kinetic diameters showing similar permeation performance through a silica membrane $[67,68]$. Single gas permeation was also carried for $\mathrm{H}_{2}$ and Ar prior to the binary mixture testing. Again, single Ar permeation did not produce permeate flows, thus below the minimum detectable level similar to the case of $\mathrm{CO}_{2}$ as mentioned above. After the $\mathrm{H}_{2}$ single gas permeation test, $\mathrm{H}_{2}$ and $\mathrm{Ar}$ mixture separation was measured for feed compositions from $90 \%$, $70 \%, 50 \%$, and $30 \%$ down to $20 \% \mathrm{H}_{2}$. The $\mathrm{H}_{2}$ feed fraction was reduced step-wise after each day of testing [61]. 
The $\mathrm{H}_{2}$ permeance rate is shown in Figure 8. Unlike the test for $\mathrm{He}$, it is interesting to observe that the $\mathrm{H}_{2}$ permeance is not constant. These unusual results suggest that $\mathrm{H}_{2}$ is possibly reducing the cobalt oxide embedded in the silica matrix, thus leading to a different micropore structure. Based on Ballinger et al.'s study, the exposure to $\mathrm{H}_{2}$ could reduce the metal oxide and widen the neck of pores [22]. To ensure a systematic study, each feed fraction was tested in a full single day, and this experiment was carried out in order from $100 \% \mathrm{H}_{2}$ down to $20 \% \mathrm{H}_{2}$. The results in Figure 8 implied that the reaction between membrane material and $\mathrm{H}_{2}$ is a function of $\mathrm{H}_{2}$ exposure time and $\mathrm{H}_{2}$ concentration in the feed gas. This will be discussed in detail in the following section.

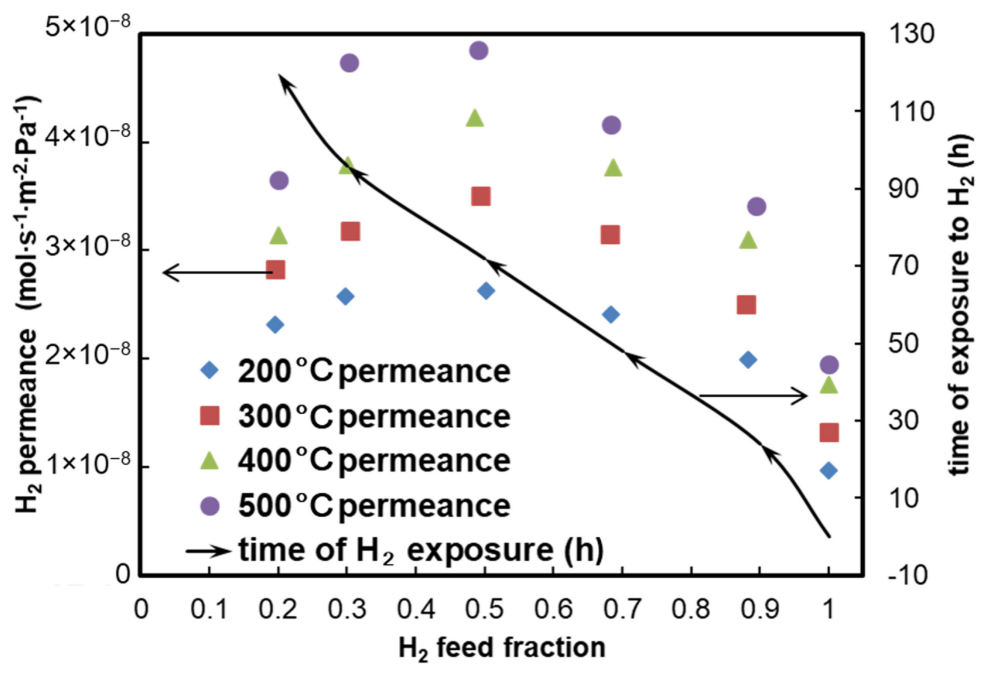

Figure 8. The permeation performance of $\mathrm{H}_{2}$.

The separation of $\mathrm{He} / \mathrm{CO}_{2}$ shows that the presence of $\mathrm{CO}_{2}$ did not significantly hinder the $\mathrm{He}$ permeance, though the flow rates increased with He feed partial pressure, which in turn caused a higher driving force or pressure difference. The apparent activation energy for He permeation has an average value of $6.3 \mathrm{~kJ} \cdot \mathrm{mol}^{-1}$ with $4.8 \%$ fluctuation for all the feed fractions.

However, it is interesting to observe that the $\mathrm{H}_{2}$ permeance was higher for gas mixtures than for the pure gas. Miller et al. [69] and Ji et al. [61] reported that cobalt oxide embedded in silica undergoes reduction after exposure to $\mathrm{H}_{2}$, resulting in pore size enlargement. As the single $\mathrm{H}_{2}$ gas permeation was tested at the beginning in this series of experiments, the permeance was the lowest as the membrane was just exposed to $\mathrm{H}_{2}$ for a short time and possibly in an oxidized state. After one day (24 h) of exposure to $\mathrm{H}_{2}$, mixed gas separation was carried out from $90 \% \mathrm{H}_{2}$ and was observed that the membrane permeance increased by about two times in the reduced state than in the oxidized state, thus confirming the redox effect of $\mathrm{H}_{2}$ on the membrane.

From Equation (15), the apparent activation energies before and after reduction can be obtained from the permeance at different temperatures. The apparent activation energy was reduced from $7.3 \mathrm{~kJ} \cdot \mathrm{mol}^{-1}$ (first day testing using pure $\mathrm{H}_{2}$ ) to $5.2 \mathrm{~kJ} \cdot \mathrm{mol}^{-1}$ (5th day testing using $30 \% \mathrm{H}_{2}$ ). Activation energy is an energy barrier to overcome during permeation. Figures 3 and 4 have demonstrated that in the range of $<5 \AA$ the L-J potential which acts as a barrier increased when the pore size is reduced. As there is a correlation between the apparent activation energy and pore size [70-72], this implies that the change of pore size is responsible for the reduction of cobalt oxide.

Figure 9 shows that when $r_{\mathrm{O}}=0.1402 \mathrm{~nm}$ and $r_{\mathrm{m}}=0.2657 \mathrm{~nm}$, the Rayleigh distribution gives the closest apparent activation energy to the experimental value for the oxidized membrane. For reduced membrane, the best fitting value is $r_{\mathrm{o}}=0.1400 \mathrm{~nm}$ and $r_{\mathrm{m}}=0.2673 \mathrm{~nm}$. The pore size distribution was derived from the fitting to $\mathrm{He}$ and $\mathrm{H}_{2}$ activation energies. If other gases could also permeate across this membrane, the pore size distribution estimated by fitting with permeation activation energies of more gases would be more reliable. But unfortunately other gases were impermeable through this 
membrane. The pore size distributions of these two states were displayed in Figure 10. The peak of inner diameter distribution for the oxidized membrane is $d_{\mathrm{i}}=0.2514 \mathrm{~nm}$, and the peak for the reduced membrane is $d_{\mathrm{i}}=0.2546 \mathrm{~nm}$. There are significant portion of pores below $d_{\mathrm{i}}<0.3 \mathrm{~nm}$ that are below the detectable limit of a traditional method by adsorption of $\mathrm{N}_{2}, \operatorname{Ar}$ or $\mathrm{CO}_{2}$.

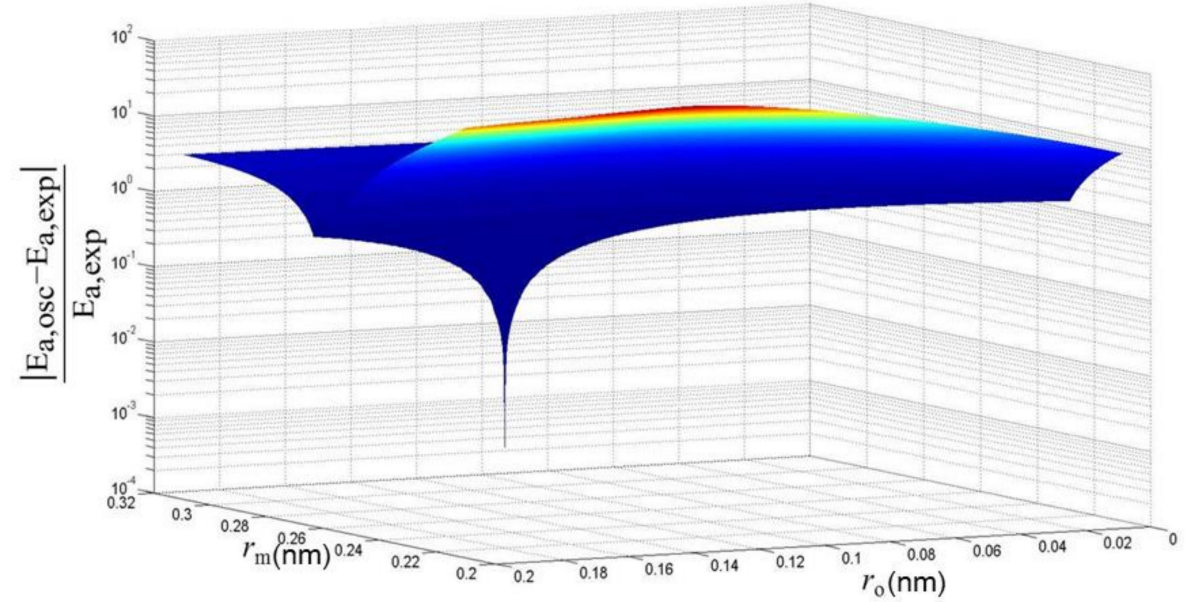

Figure 9. Screening of $\left(r_{\mathrm{o}}, r_{\mathrm{m}}\right)$ to detect minimum deviation to the experimental activation energy.

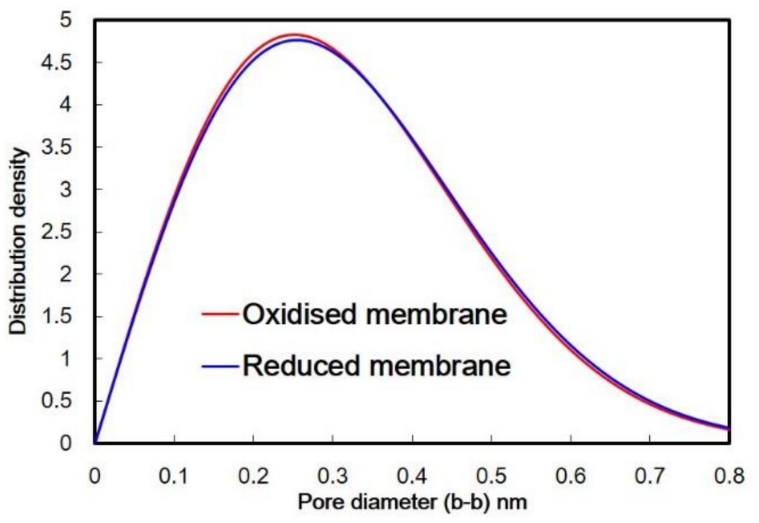

Figure 10. Calculated pore size distribution of silica membrane in oxidized state and reduced state.

With a pore size distribution, effective medium theory (EMT) could compute the effective transport conductance $\lambda_{\mathrm{e}}$. Therefore, the bulk permeability from EMT is

$$
P=\frac{\lambda_{\mathrm{e}}}{\left\langle r_{\mathrm{p}}^{2}\right\rangle}
$$

Based on the PSD estimated for the oxidized membrane and reduced membrane in Figure 10, the bulk permeability is calculated for $\mathrm{He}, \mathrm{H}_{2}$. The calculated permeability for $\mathrm{He}$ and $\mathrm{H}_{2}$ was also compared with available experimental permeability as shown in Figure 11. The modelled permeability based on the pore size distribution above fits well with actual pore size distribution. This suggests that the estimated pore size distribution in Figure 10 could be a reasonable representation of the real pore size distribution.

The bulk permeabilities of $\mathrm{Ar}$ and $\mathrm{CO}_{2}$ from these two pore size distribution are at least five orders of magnitude lower than for $\mathrm{He}$ and $\mathrm{H}_{2}$. The distribution in Figure 10 shows that there is also a significant portion of pores larger than $\mathrm{Ar}$ and $\mathrm{CO}_{2}$ kinetic diameter. However, it should be noted that a pathway for permeation consists of a serious of connected pores and only the narrowest part restricts the permeation, thus the permeability for $\mathrm{Ar}$ and $\mathrm{CO}_{2}$ are much lower. This low permeability is why the permeation of $\mathrm{Ar}$ and $\mathrm{CO}_{2}$ could not be measured by the bubble flow meter. 


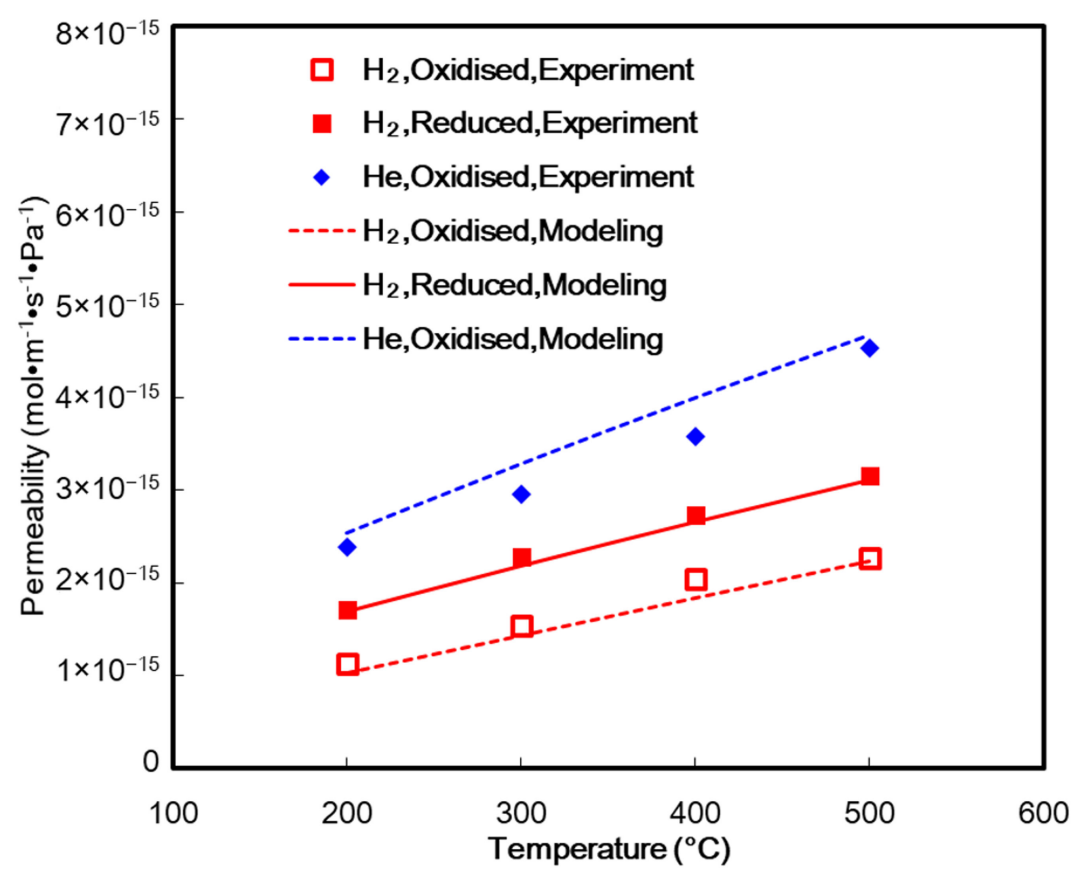

Figure 11. Comparison of permeability obtained from calculation and experiment.

\section{Conclusion}

The findings in this work supports the use of membrane permeation results to determine the apparent activation energy, and on coupling with the oscillator model permeation data can be used to estimate the pore size distribution. Therefore, better accuracy of pore sizes and pore size distribution can be achieved, which is otherwise not readily possible for xerogels and conventional characterization techniques. This study demonstrated that a Rayleigh distribution with $r_{\mathrm{o}}=0.1402 \mathrm{~nm}$ and $r_{\mathrm{m}}=0.2657 \mathrm{~nm}$ was a reasonable representation of the pore size distribution in a silica based membrane. Based on this estimated pore size distribution, the calculated permeability fitted well the experimental permeability. This method proved to be robust for calculating the pore size for cylindrical pore geometry and known material properties.

Author Contributions: G.J. designed and conducted the experiment, wrote the codes, analyzed the data, and wrote the manuscript; X.G. contributed in the modelling work; S.S. contributed in the membrane fabrication; S.K.B. provided the oscillator model and revised the manuscript; G.W. and K.H. contributed in supervision; J.C.D.d.C. contributed in supervision, membrane test and manuscript revision.

Funding: This research was funded by Australian Research Council via the Future Fellowship Program grant number FT130100405, National Natural Science Foundation of China grant number: 21878147, and Fundamental Research Funds for the Central Universities grant number: DUT18RC(3)036.

Acknowledgments: J.C.D.d.C. thanks the support from Australian Research Council via the Future Fellowship Program (FT130100405). X.G. thanks the financial support from National Natural Science Foundation of China (Grant number: 21878147). G.J. would appreciate the financial support from the Fundamental Research Funds for the Central Universities (Grant number: DUT18RC(3)036), and the technical support from Ling Yun HPC in Dalian University of Technology.

Conflicts of Interest: The authors declare no conflict of interest.

\section{References}

1. Ji, G.; Wang, G.; Hooman, K.; Bhatia, S.; Diniz da Costa, J.C. Scale-Up Design Analysis and Modelling of Cobalt Oxide Silica Membrane Module for Hydrogen Processing. Processes 2013, 1, 49-66. [CrossRef]

2. Ji, G.; George, A.; Skoulou, V.; Reed, G.; Millan, M.; Hooman, K.; Bhatia, S.K.; Diniz da Costa, J.C. Investigation and simulation of the transport of gas containing mercury in microporous silica membranes. Chem. Eng. Sci. 2018, 190, 286-296. [CrossRef] 
3. Smart, S.; Lin, C.X.C.; Ding, L.; Thambimuthu, K.; Diniz da Costa, J.C. Ceramic membranes for gas processing in coal gasification. Energy Environ. Sci. 2010, 3, 268-278. [CrossRef]

4. Ji, G.; Yao, J.G.; Clough, P.T.; Diniz da Costa, J.C.; Anthony, E.J.; Fennell, P.S.; Wang, W.; Zhao, M. Enhanced hydrogen production from thermochemical processes. Energy Environ. Sci. 2018, 11, 2647-2672. [CrossRef]

5. De Vos, R.M.; Verweij, H. High-Selectivity, High-Flux Silica Membranes for Gas Separation. Science 1998, 279, 1710-1711. [CrossRef] [PubMed]

6. Raman, N.K.; Brinker, C.J. Organic "template" approach to molecular sieving silica membranes. J. Membr. Sci. 1995, 105, 273-279. [CrossRef]

7. Kusakabe, K.; Sakamoto, S.; Saie, T.; Morooka, S. Pore structure of silica membranes formed by a sol-gel technique using tetraethoxysilane and alkyltriethoxysilanes. Sep. Purif. Technol. 1999, 16, 139-146. [CrossRef]

8. Kanezashi, M.; Fujita, T.; Asaeda, M. Nickel-Doped Silica Membranes for Separation of Helium from Organic Gas Mixtures. Sep. Sci. Technol. 2005, 40, 225-238. [CrossRef]

9. Kanezashi, M.; Asaeda, M. Hydrogen permeation characteristics and stability of Ni-doped silica membranes in steam at high temperature. J. Membr. Sci. 2006, 271, 86-93. [CrossRef]

10. Battersby, S.; Duke, M.C.; Liu, S.; Rudolph, V.; Diniz da Costa, J.C. Metal doped silica membrane reactor: Operational effects of reaction and permeation for the water gas shift reaction. J. Membr. Sci. 2008, 316, 46-52. [CrossRef]

11. Uhlmann, D.; Liu, S.; Ladewig, B.P.; Diniz da Costa, J.C. Cobalt-doped silica membranes for gas separation. J. Membr. Sci. 2009, 326, 316-321. [CrossRef]

12. Uhlmann, D.; Smart, S.; Diniz da Costa, J.C. High temperature steam investigation of cobalt oxide silica membranes for gas separation. Sep. Purif. Technol. 2010, 76, 171-178. [CrossRef]

13. Uhlmann, D.; Smart, S.; Diniz da Costa, J.C. $\mathrm{H}_{2} \mathrm{~S}$ stability and separation performance of cobalt oxide silica membranes. J. Membr. Sci. 2011, 380, 48-54. [CrossRef]

14. Liu, L.; Wang, D.K.; Martens, D.L.; Smart, S.; Diniz da Costa, J.C. Influence of sol-gel conditioning on the cobalt phase and the hydrothermal stability of cobalt oxide silica membranes. J. Membr. Sci. 2015, 475, 425-432. [CrossRef]

15. Boffa, V.; Blank, D.H.A.; Ten Elshof, J.E. Hydrothermal stability of microporous silica and niobia-silica membranes. J. Membr. Sci. 2008, 319, 256-263. [CrossRef]

16. Kanezashi, M.; Fuchigami, D.; Yoshioka, T.; Tsuru, T. Control of Pd dispersion in sol-gel-derived amorphous silica membranes for hydrogen separation at high temperatures. J. Membr. Sci. 2013, 439, 78-86. [CrossRef]

17. Yoshida, K.; Hirano, Y.; Fujii, H.; Tsuru, T.; Asaeda, M. Hydrothermal Stability and Performance of Silica-Zirconia Membranes for Hydrogen Separation in Hydrothermal Conditions. J. Chem. Eng. Jpn. 2001, 34, 523-530. [CrossRef]

18. Gu, Y.; Oyama, S.T. Permeation properties and hydrothermal stability of silica-titania membranes supported on porous alumina substrates. J. Membr. Sci. 2009, 345, 267-275. [CrossRef]

19. Fotou, G.P.; Lin, Y.S.; Pratsinis, S.E. Hydrothermal stability of pure and modified microporous silica membranes. J. Mater. Sci. 1995, 30, 2803-2808. [CrossRef]

20. Darmawan, A.; Motuzas, J.; Smart, S.; Julbe, A.; Diniz da Costa, J.C. Binary iron cobalt oxide silica membrane for gas separation. J. Membr. Sci. 2015, 474, 32-38. [CrossRef]

21. Darmawan, A.; Motuzas, J.; Smart, S.; Julbe, A.; Diniz da Costa, J.C. Temperature dependent transition point of purity versus flux for gas separation in Fe/Co-silica membranes. Sep. Purif. Technol. 2015, 151, 284-291. [CrossRef]

22. Ballinger, B.; Motuzas, J.; Smart, S.; Diniz da Costa, J.C. Palladium cobalt binary doping of molecular sieving silica membranes. J. Membr. Sci. 2014, 451, 185-191. [CrossRef]

23. Ballinger, B.; Motuzas, J.; Miller, C.R.; Smart, S.; Diniz da Costa, J.C. Nanoscale assembly of lanthanum silica with dense and porous interfacial structures. Sci. Rep. 2015, 5, 8210. [CrossRef] [PubMed]

24. Battersby, S.; Tasaki, T.; Smart, S.; Ladewig, B.; Liu, S.; Duke, M.C.; Rudolph, V.; Diniz da Costa, J.C. Performance of cobalt silica membranes in gas mixture separation. J. Membr. Sci. 2009, 329, 91-98. [CrossRef]

25. Meixner, D.L.; Dyer, P.N. Characterization of the transport properties of microporous inorganic membranes. J. Membr. Sci. 1998, 140, 81-95. [CrossRef]

26. Duke, M.C.; Pas, S.J.; Hill, A.J.; Lin, Y.S.; Diniz da Costa, J.C. Exposing the Molecular Sieving Architecture of Amorphous Silica Using Positron Annihilation Spectroscopy. Adv. Funct. Mater. 2008, 18, 3818-3826. [CrossRef] 
27. Diniz da Costa, J.C.; Lu, G.Q.; Rudolph, V.; Lin, Y.S. Novel molecular sieve silica (MSS) membranes: Characterisation and permeation of single-step and two-step sol-gel membranes. J. Membr. Sci. 2002, 198, 9-21. [CrossRef]

28. Gopalakrishnan, S.; Diniz da Costa, J.C. Hydrogen gas mixture separation by CVD silica membrane. J. Membr. Sci. 2008, 323, 144-147. [CrossRef]

29. Gopalakrishnan, S.; Yoshino, Y.; Nomura, M.; Nair, B.N.; Nakao, S.-I. A hybrid processing method for high performance hydrogen-selective silica membranes. J. Membr. Sci. 2007, 297, 5-9. [CrossRef]

30. Zivkovic, T. Thin Supported Silica Membranes; The University Twente: Enschede, The Netherlands, 2007.

31. Ha, H.Y.; Nam, S.W.; Lee, W.K. Chemical vapor deposition of hydrogen-permselective silica films on porous glass supports from tetraethylorthosilicate. J. Membr. Sci. 1993, 85, 279-290.

32. Ghasemzadeh, K.; Aghaeinejad-Meybodi, A.; Vaezi, M.J.; Gholizadeh, A.; Abdi, M.A.; Babaluo, A.A.; Haghighi, M.; Basile, A. Hydrogen production via silica membrane reactor during the methanol steam reforming process: Experimental study. RSC Adv. 2015, 5, 95823-95832. [CrossRef]

33. Kanezashi, M.; Sasaki, T.; Tawarayama, H.; Nagasawa, H.; Yoshioka, T.; Ito, K.; Tsuru, T. Experimental and Theoretical Study on Small Gas Permeation Properties through Amorphous Silica Membranes Fabricated at Different Temperatures. J. Phys. Chem. C 2014, 118, 20323-20331. [CrossRef]

34. Kanezashi, M.; Sasaki, T.; Tawarayama, H.; Yoshioka, T.; Tsuru, T. Hydrogen Permeation Properties and Hydrothermal Stability of Sol-Gel-Derived Amorphous Silica Membranes Fabricated at High Temperatures. J. Am. Ceram. Soc. 2013, 96, 2950-2957. [CrossRef]

35. Yoshioka, T.; Nakanishi, E.; Tsuru, T.; Asaeda, M. Experimental studies of gas permeation through microporous silica membranes. AlChE J. 2001, 47, 2052-2063. [CrossRef]

36. De Vos, R.M.; Maier, W.F.; Verweij, H. Hydrophobic silica membranes for gas separation. J. Membr. Sci. 1999, 158, 277-288. [CrossRef]

37. Krishna, R.; Baur, R. Modelling issues in zeolite based separation processes. Sep. Purif. Technol. 2003, 33, 213-254. [CrossRef]

38. Van den Bergh, J.; Ban, S.; Vlugt, T.J.H.; Kapteijn, F. Modeling the Loading Dependency of Diffusion in Zeolites: The Relevant Site Model Extended to Mixtures in DDR-Type Zeolite. J. Phys. Chem. C 2009, 113, 21856-21865. [CrossRef]

39. Ji, G.; Wang, G.; Hooman, K.; Bhatia, S.; Diniz da Costa, J.C. Simulation of binary gas separation through multi-tube molecular sieving membranes at high temperatures. Chem. Eng. J. 2013, 218, 394-404. [CrossRef]

40. Burggraaf, A.J. Single gas permeation of thin zeolite (MFI) membranes: Theory and analysis of experimental observations. J. Membr. Sci. 1999, 155, 45-65. [CrossRef]

41. Krishna, R. A unified approach to the modelling of intraparticle diffusion in adsorption processes. Gas Sep. Purif. 1993, 7, 91-104. [CrossRef]

42. Krishna, R.; Van Baten, J.M. A simplified procedure for estimation of mixture permeances from unary permeation data. J. Membr. Sci. 2011, 367, 204-210. [CrossRef]

43. Thornton, A.W.; Hilder, T.; Hill, A.J.; Hill, J.M. Predicting gas diffusion regime within pores of different size, shape and composition. J. Membr. Sci. 2009, 336, 101-108. [CrossRef]

44. Bonilla, M.R.; Bhatia, S.K. The low-density diffusion coefficient of soft-sphere fluids in nanopores: Accurate correlations from exact theory and criteria for applicability of the Knudsen model. J. Membr. Sci. 2011, 382, 339-349. [CrossRef]

45. Bhatia, S.K. Tractable molecular theory of transport of Lennard-Jones fluids in nanopores. J. Chem. Phys. 2004, 120, 4472-4485. [CrossRef] [PubMed]

46. Tomozawa, M. Chapter 3-Amorphous silica. In Silicon-Based Material and Devices; Nalwa, H.S., Ed.; Academic Press: Burlington, NJ, USA, 2001; pp. 127-154.

47. Lang, N.R.; Münster, S.; Metzner, C.; Krauss, P.; Schürmann, S.; Lange, J.; Aifantis, K.E.; Friedrich, O.; Fabry, B. Estimating the 3D Pore Size Distribution of Biopolymer Networks from Directionally Biased Data. Biophys. J. 2013, 105, 1967-1975. [CrossRef] [PubMed]

48. Metzner, C.; Krauss, P.; Fabry, B. Poresizes in random line networks. arXiv 2011, arXiv:1110.1803v1.

49. Phirani, J.; Pitchumani, R.; Mohanty, K.K. Transport Properties of Hydrate Bearing Formations from Pore-Scale Modeling. In Proceedings of the SPE Annual Technical Conference and Exhibition, New Orleans, LA, USA, 4-7 October 2009. 
50. Panfilov, M.; Panfilova, I.; Stepanyants, Y. Mechanisms of Particle Transport Acceleration in Porous Media. Transp. Porous Media 2008, 74, 49-71. [CrossRef]

51. Park, C.-Y.; Ihm, S.-K. New hypotheses for Mercury porosimetry with percolation approach. AlChE J. 1990, 36, 1641-1648. [CrossRef]

52. Mishra, B.K.; Sharma, M.M. Measurement of pore size distributions from capillary pressure curves. AlChE J. 1988, 34, 684-687. [CrossRef]

53. Bhatia, S.K. Modeling Pure Gas Permeation in Nanoporous Materials and Membranes. Langmuir 2010, 26, 8373-8385. [CrossRef] [PubMed]

54. Jepps, O.G.; Bhatia, S.K.; Searles, D.J. Wall Mediated Transport in Confined Spaces: Exact Theory for Low Density. Phys. Rev. Lett. 2003, 91, 126102. [CrossRef] [PubMed]

55. Zhang, L.; Seaton, N.A. Prediction of the effective diffusivity in pore networks close to a percolation threshold. AlChE J. 1992, 38, 1816-1824. [CrossRef]

56. Burganos, V.N.; Sotirchos, S.V. Diffusion in pore networks: Effective medium theory and smooth field approximation. AlChE J. 1987, 33, 1678-1689. [CrossRef]

57. Kirkpatrick, S. Percolation and Conduction. Rev. Mod. Phys. 1973, 45, 574-588. [CrossRef]

58. Landauer, R. The Electrical Resistance of Binary Metallic Mixtures. J. Appl. Phys. 1952, 23, 779-784. [CrossRef]

59. Bhatia, S.K. Directional autocorrelation and the diffusional tortuosity of capillary porous media. J. Catal. 1985, 93, 192-196. [CrossRef]

60. Bhatia, S.K. Stochastic theory of transport in inhomogeneous media. Chem. Eng. Sci. 1986, 41, 1311-1324. [CrossRef]

61. Ji, G.; Smart, S.; Bhatia, S.K.; Diniz da Costa, J.C. Improved pore connectivity by the reduction of cobalt oxide silica membranes. Sep. Purif. Technol. 2015, 154, 338-344. [CrossRef]

62. Bakker, W.J.W.; Kapteijn, F.; Poppe, J.; Moulijn, J.A. Permeation characteristics of a metal-supported silicalite-1 zeolite membrane. J. Membr. Sci. 1996, 117, 57-78. [CrossRef]

63. Kapteijn, F.; Bakker, W.J.W.; Van de Graaf, J.; Zheng, G.; Poppe, J.; Moulijn, J.A. Permeation and separation behaviour of a silicalite-1 membrane. Catal. Today 1995, 25, 213-218. [CrossRef]

64. Smart, S.; Vente, J.F.; Diniz da Costa, J.C. High temperature $\mathrm{H}_{2} / \mathrm{CO}_{2}$ separation using cobalt oxide silica membranes. Int. J. Hydrog. Energy 2012, 37, 12700-12707. [CrossRef]

65. Bhatia, S.K.; Nicholson, D. Some pitfalls in the use of the Knudsen equation in modelling diffusion in nanoporous materials. Chem. Eng. Sci. 2011, 66, 284-293. [CrossRef]

66. Gao, X.; Diniz da Costa, J.C.; Bhatia, S.K. Adsorption and transport of gases in a supported microporous silica membrane. J. Membr. Sci. 2014, 460, 46-61. [CrossRef]

67. Yacou, C.; Smart, S.; Diniz da Costa, J.C. Long term performance cobalt oxide silica membrane module for high temperature $\mathrm{H}_{2}$ separation. Energy. Environ. Sci. 2012, 5, 5820-5832. [CrossRef]

68. Ji, G.; Wang, G.; Hooman, K.; Bhatia, S.; Diniz da Costa, J.C. The fluid dynamic effect on the driving force for a cobalt oxide silica membrane module at high temperatures. Chem. Eng. Sci. 2014, 111, 142-152. [CrossRef]

69. Miller, C.R.; Wang, D.K.; Smart, S.; Diniz da Costa, J.C. Reversible Redox Effect on Gas Permeation of Cobalt Doped Ethoxy Polysiloxane (ES40) Membranes. Sci. Rep. 2013, 3, 1-6. [CrossRef] [PubMed]

70. Xiao, J.; Wei, J. Diffusion mechanism of hydrocarbons in zeolites-I. Theory. Chem. Eng. Sci. 1992, 47, 1123-1141. [CrossRef]

71. Xiao, J.; Wei, J. Diffusion mechanism of hydrocarbons in zeolites-II. Analysis of experimental observations. Chem. Eng. Sci. 1992, 47, 1143-1159. [CrossRef]

72. Hacarlioglu, P.; Lee, D.; Gibbs, G.V.; Oyama, S.T. Activation energies for permeation of He and H2 through silica membranes: An ab initio calculation study. J. Membr. Sci. 2008, 313, 277-283. [CrossRef]

(C) 2018 by the authors. Licensee MDPI, Basel, Switzerland. This article is an open access article distributed under the terms and conditions of the Creative Commons Attribution (CC BY) license (http:/ / creativecommons.org/licenses/by/4.0/). 